\title{
Ratio of basin lag times for runoff and sediment yield processes recorded in various environments
}

\author{
KAZIMIERZ BANASIK \& AGNIESZKA HEJDUK \\ Warsaw University of Life Sciences - SGGW, Faculty of Civil and Environmental Engineering, 166 Nowoursynowska \\ str., PL-02-787 Warsaw, Poland \\ kazimierz banasik@,sggw.pl
}

\begin{abstract}
River basin lag time (LAG), defined as the elapsed time between the occurrence of the centroids of the effective rainfall intensity hyetograph and the storm runoff hydrograph, is an important factor in determining the time to peak and the peak value of the instantaneous unit hydrograph (IUH). In the procedure of predicting a sedimentgraph (suspended sediment load as a function of time), the equivalent parameter is the lag time for the sediment yield $\left(\mathrm{LAG}_{\mathrm{s}}\right)$, which is defined as the elapsed time between the occurrence of the centroids of sediment production during a storm event and the observed sedimentgraph at the gauging station. Data of over 150 events recorded in 11 small river catchments (located in Poland, Germany, UK and USA) with a drainage area of $0.02 \mathrm{~km}^{2}$ to $82 \mathrm{~km}^{2}$ have been analysed to estimate the ratio of $\mathrm{LAG}_{\mathrm{s}} / \mathrm{LAG}$. The ratio, in majority of cases was smaller than 1 , and decreased with increase of river basin slope. Special attention is given to the data collected in a small agricultural catchment and also during snowmelt periods, which is located in central Poland.
\end{abstract}

Key words small catchment; soil erosion; suspended sediment; sediment graph; snowmelt event; IUSG

\section{INTRODUCTION}

Sedimentgraphs (graphs of suspended sediment load associated with hydrographs caused by rainfall or snowmelt) are essential for: (i) sediment yield assessment, (ii) providing input data for prediction models of sediment deposition in reservoirs, (iii) designing efficient sediment control structures, and for (iv) water quality predictions. One of the first studies on sedimentgraphs, i.e. on the relationship between the ordinates of the streamflow hydrograph and the sedimentgraph for a small catchment was undertaken by Johnson (1943). He developed a distribution graph of suspended sediment concentration which is analogous to a hydrograph. His results, which demonstrated that there was commonly a rapid initial rise of sediment concentration with increasing discharge and that the suspended sediment concentration reached a peak before the discharge peak, have been widely applied as a general behavioural model of suspended sediment response to heavy rainfall, and confirmed in further studies (Walling and Webb 1982, Froehlich 1986, 1991). Johnson's idea was implemented in a sedimentgraph model by Williams (1978). This was further developed for predicting and regenerating the suspended sediment load as a response of a small catchment to heavy rainfall (Banasik and Woodward 1992, Banasik and Blay 1994, Banasik and Walling 1996). A new definition of the instantaneous unit sedimentgraph (IUSG) was also developed (Banasik 1994, 1995; Banasik and Walling 1996) and incorporated into the sedimentgraph model (SEGMO), based on a lumped parametric approach.

River basin lag times, i.e. lag time for runoff (LAG), defined as the elapsed time between the occurrence of the centroids of the effective rainfall intensity hyetograph and the direct runoff hydrograph, and lag time for the sediment yield $\left(\mathrm{LAG}_{\mathrm{s}}\right)$, defined as the elapsed time between the occurrence of the centroids of sediment production during a storm event and the observed sedimentgraph at the gauging station, are needed for estimating the IUH and IUSG parameters. The aim of the study is to present relationships between $L A G_{s}$ and LAG for 11 small river catchments located in Poland, Germany, UK and USA, in which over 150 rainfall-runoff events were recorded, as well as to describe the IUSG procedure, for parameter description of which, the lag times are needed.

\section{DESCRIPTION OF IUSG PROCEDURE AND PARAMETERS}

The IUSG is defined as the time distribution of sediment generated from an instantaneous burst of rainfall producing one unit of sediment. The IUSG presented here is based on the IUH developed 
by Nash (1957) i.e.:

$$
u(t)=\frac{1}{k \cdot \Gamma(N)} \cdot(t / k)^{N-1} \cdot \exp (-t / k)
$$

and the first-order kinetic equation written in dimensionless form and termed the dimensionless sediment concentration distribution (DSCD):

$$
c(t)=\exp (-B \cdot t)
$$

where $u(t)$ are the ordinates of the IUH (1/hour), $N$ and $k$ are the Nash model parameters: $N$ is number of reservoirs (-), $k$ is the retention time of reservoir (hours), $\Gamma(N)$ is gamma function, $c(t)$ are the ordinates of the DSCD (-), $B$ is sediment routing coefficient (1/hour), and $t$ is time (hours).

The IUSG is calculated by the formula:

$$
s(t)=\frac{u(t) \cdot c(t)}{\int_{0}^{\infty} u(t) \cdot c(t) \mathrm{d} t}
$$

which, after inserting equations (1) and (2), produces the following formula (Banasik, 1994):

$$
s(t)=\frac{B \cdot k+1}{k \cdot \Gamma(N)} \cdot[t(B+1 / k)]^{N-1} \cdot \exp [-t(B+1 / k)] \quad \text { for } B \geq-1 / k
$$

where $s(t)$ are the IUSG ordinates (1/hour). The IUSG has three parameters $N$ and $k$ which are also IUH parameters and a third parameter $B$, the sediment routing coefficient.

The characteristic values of the IUSG (i.e. time to peak) can be calculated from the formula:

$$
t_{p s}=\frac{(N-1) \cdot k}{1+B \cdot k}
$$

and the maximum ordinate of IUSG can be computed from the equation:

$$
s_{p}=\frac{1+B \cdot k}{k \cdot \Gamma(N)} \cdot \frac{(N-1)^{N-1}}{\exp (N-1)}
$$

where $t_{p s}$ is the time to peak of IUSG (hour), and $s_{p}$ is the maximum ordinate of IUSG (1/hour).

As the respective values for IUH are calculated from the equations:

$$
t_{p}=(N-1) \cdot k
$$

and:

$$
u_{p}=\frac{1}{k \cdot \Gamma(N)} \cdot \frac{(N-1)^{N-1}}{\exp (N-1)}
$$

where $t_{p}$ is time to peak of IUH (hour), and $u_{p}$ is the maximum ordinate of IUH (1/hour), so the ratio of the characteristic values of IUSG and IUH can be computed from the formulae:

$$
\frac{t_{p s}}{t_{p}}=\frac{1}{(1+B \cdot k)}
$$

and:

$$
\frac{s_{p}}{u_{p}}=1+B \cdot k
$$

It is clear that when $B$ equals zero the characteristic values of IUH and IUSG are the same and the right side of equation (4) assumes the form of the IUH (equation (1)). It can also be found from equation (9), that for $B>0$, the time to peak of the IUSG is shorter than the time to peak of the IUH, and the IUSG peak is higher than the IUH peak (equation (10)). 


\section{USE OF LAG TIMES IN ESTIMATION OF IUSG PARAMETERS}

One of the characteristic values in rainfall-runoff models is the retention of the system or the lag time, defined earlier. For the IUH derived by Nash, the lag time is estimated using the formula:

$$
L A G=N \cdot k
$$

For the IUSG, the lag time $\left(\mathrm{LAG}_{\mathrm{s}}\right)$ can be calculated using equation:

$$
L A G_{s}=\frac{N \cdot k}{1+B \cdot k}
$$

Making use of equations (11) and (12), the routing coefficient B can be computed using the formula:

$$
B=\left(L A G / L A G_{s}-1\right) / k
$$

Since $L A G, L A G_{s}$ and $k$ can be estimated from rainfall, runoff and suspended sediment data, the routing coefficient $B$, can be estimated using equation (13).

Inserting equation (13) into equations (9) and (10) one derives very useful formulae for the relationships between the characteristic values of the IUH and the IUSG. The ratios of lag times take the following forms:

$$
\begin{aligned}
\frac{t_{p s}}{t_{p}} & =\frac{L A G_{s}}{L A G} \\
\frac{s_{p}}{u_{p}} & =\frac{L A G}{L A G_{s}}
\end{aligned}
$$

Equations (14) and (15) show the importance of hydrograph and sedimentgraph lag times in demonstrating how the IUSG characteristics can easily be derived from IUH characteristics.

Using measured data from rainfall-runoff events, the lag time can be calculated as:

$$
L A G=M_{1 Q}-M_{1 P}
$$

where $M_{I Q}$ and $M_{I P}$ are the first statistical moments of the direct runoff hydrograph and the effective rainfall hyetograph (h), respectively. Based on measured data, the lag time for the sedimentgraph $\left(L A G_{s}\right)$ is defined as time elapsed between the centroids of the sediment production graph (similar to effective rainfall hyetograph) and the sedimentgraph, and can be computed from the formula:

$$
L A G_{s}=M_{1 S}-M_{1 E}
$$

where $M_{I S}$ and $M_{I E}$ are the first statistical moments of the graph of direct suspended sediment rate, and the graph of sediment production (h), respectively (Banasik et al. 2005).

Data of 152 recorded rainfall-runoff events in 11 small river catchments located in Poland, Germany, UK and USA were analysed to investigate the relationship between $L A G_{s}$ and $L A G$.

\section{DATA ANALYSED AND RESULTS}

\section{Sources of data}

The data used in this paper for estimation the values $L A G_{s} / L A G$ were collected in 11 small catchments of various land use and steepness by research units of six universities (Warsaw University of Life Sciences, Cracow Agricultural University, University of Kassel, Free University of Berlin, Exeter University and University of Illinois at Urbana-Champaign) and were analysed in depth in separate studies. Names of the catchments, their locations and some other characteristics are given in Table 1 . The mean ratio of $L A G_{s} / L A G$, estimated on the basis of recorded individual rainfall-runoff sediment yield events, for each catchment is related to the steepness of the catchments. 
Table 1 Characteristics of the catchments.

\begin{tabular}{|c|c|c|c|c|c|c|c|}
\hline No & $\begin{array}{l}\text { Catchment - } \\
\text { notation }\end{array}$ & $\begin{array}{l}\text { Catchment } \\
\text { locality }\end{array}$ & $\begin{array}{l}\text { Catchment } \\
\text { area } \\
\left(\mathrm{km}^{2}\right)\end{array}$ & $\begin{array}{l}\text { Number } \\
\text { of events }\end{array}$ & $\begin{array}{l}\text { Average } \\
\text { value of } \\
\operatorname{Lag}_{s} / L a g\end{array}$ & $\begin{array}{l}\text { Catchment } \\
\text { steepness } \\
(\mathrm{m} / \mathrm{km})\end{array}$ & $\begin{array}{l}\text { Refere } \\
\text { nces }\end{array}$ \\
\hline 1 & Zagożdżonka Z1 & PL-lowland & 23.4 & 21 & 0.90 & 5.5 & $\left.\mathrm{R}-1^{*}\right)$ \\
\hline 2 & Zagożdżonka - Z2 & PL-lowland & 82.4 & 4 & 0.59 & 4.1 & $\mathrm{R}-2$ \\
\hline 3 & Poniczanka & PL-Carpathians & 33.1 & 12 & 0.86 & 90.1 & $\mathrm{R}-3$ \\
\hline 4 & Mszanka & PL-Carpathians & 51.0 & 12 & 0.79 & 77.0 & $\mathrm{R}-3$ \\
\hline 5 & Kasinka & PL-Carpathians & 32.0 & 13 & 0.93 & 115 & $\mathrm{R}-3$ \\
\hline 6 & Lubieńka & PL-Carpathians & 48.7 & 16 & 0.96 & 77.9 & $\mathrm{R}-3$ \\
\hline 7 & Skawica & PL-Carpathians & 48.6 & 11 & 0.72 & 166 & $\mathrm{R}-3$ \\
\hline 8 & Bauna & D - Hessen & 45.0 & 10 & 0.66 & 42.2 & $\mathrm{R}-2$ \\
\hline 9 & Lainbach & D - Bavaria & 15.8 & 6 & 0.34 & 201 & $\mathrm{R}-4$ \\
\hline 10 & Dart & UK - Devon & 46.0 & 39 & 0.85 & 33.6 & $\mathrm{R}-5$ \\
\hline 11 & LVR & US - Illinois & 0.023 & 8 & 0.78 & 19.0 & $\mathrm{R}-6$ \\
\hline
\end{tabular}

The catchment steepness has been defined by:

$$
\Psi=\frac{H_{\max }-H_{\min }}{\sqrt{A}}
$$

$H_{\max }$ and $H_{\min }$ are maximum and minimum catchment elevation (m), and $A$ catchment area $\left(\mathrm{km}^{2}\right)$.

The Zagożdżonka catchment, monitored by Warsaw University of Life Sciences - SGGW at two stream gauging stations $\left(A\right.$ of 23.4 and $\left.82.4 \mathrm{~km}^{2}\right)$, is located in central Poland $(100 \mathrm{~km}$ south of Warsaw) and is characterised by very mild slopes, light soils and agricultural land use (mainly potato and small grain) with some forest areas. There are two types of flood events in the region: rainfall and snowmelt. The majority of the 25 rainfall events (items 1 and 2 in Table 1 ) have been recorded since 2000 (Banasik et al. 2006, Barszcz et al. 2006).

The data of five Carpathians catchments $\left(A\right.$ of $\left.32.0-51.0 \mathrm{~km}^{2}\right)$, located in southern Poland within the upper Vistula River basin, were collected by Cracow Agricultural University in the period 1976-1979. The catchments (items 3-7 in Table 1) are characterised by steep slopes and a significant ratio of forest area in the catchment areas, i.e. from 0.37 to 0.80 (Madeyski and Banasik 1989, Banasik et al. 2005).

The Bauna catchment $\left(45 \mathrm{~km}^{2}\right)$ to Kirchbauna gauging station is a typical small basin in a low mountain range in Hesse, Germany. However, the proportions of the urbanized area and of the impervious surfaces, in the period of field investigation, were $24 \%$ and $11 \%$, respectively, and are therefore relatively high. The rest of the basin consisted of arable land (33\%), woodlands (30\%) and pastures (12\%). The soils in the basin are of low permeability. The data were collected by the University of Kassel in the period of 2000-2004 (Barszcz et al. 2006).

The Lainbach creek is located in the Northern Limestone and Flysch Alps near Benediktbeuern, Upper Bavaria, about $60 \mathrm{~km}$ south of Munich. About $80 \%$ of the catchment (total area $15.8 \mathrm{~km}^{2}$ ) is covered by forest. The main sources of the sediments transported during storm events are several non-vegetated slopes. The data were collected by Free University of Berlin (Banasik and Blay 1994).

The River Dart is a west-bank tributary of the River Exe in southwest England, with a catchment area of $46 \mathrm{~km}^{2}$. The catchment has an absolute relief of $228 \mathrm{~m}$. Permanent pasture dominates the land use. The runoff and suspended sediment data were collected by the Department of Geography at the University of Exeter (Banasik and Walling 1996).

The Little Vermilion River (LVR) is located in East Central Illinois, USA, where the average annual rainfall is approximately $1010 \mathrm{~mm}$. The $\mathrm{M} 3$ watershed, from which data were used in this investigation, has silty loam soils (called Sabina and Xenia), flat topography (slopes of less than $2 \%$ ) and is totally used for row crop production, primarily corn rotated with soybeans (Banasik and Mitchell 2008). The data were collected by the University of Illinois at Urbana-Champaign. 
At the gauging stations there were various ways of data collection. The manual one was used in the earlier investigations, i.e. catchments listed as $2-7$, and automatic one (with application of sediment samplers and/or turbidity meters) used in the remaining catchments. The results of the mean values of $L A G_{s} / L A G$ estimated for various catchments are related to the catchment steepness.

\section{Ratio of lag time for runoff and sediment yield}

The averaged ratios of the lag times, i.e. $L A G_{s} / L A G$ for the considered river basins were from 0.34 for Lainbach - the very steep alpine catchment, characterised by steepness equal to 201, to 0.96 for Lubieńka, the Carpathian catchment, of steepness 77.9. For seven of the 11 considered catchments the ratios $L A G_{s} / L A G$ were in the range $0.65-0.90$, Two catchments have higher averaged ratios of the lag times than 0.90 , and two have ratios smaller than 0.65 .

The values $L A G_{s} / L A G$ versus catchment steepness are presented in Fig. 1, with two regressions, a linear one and an exponential one.

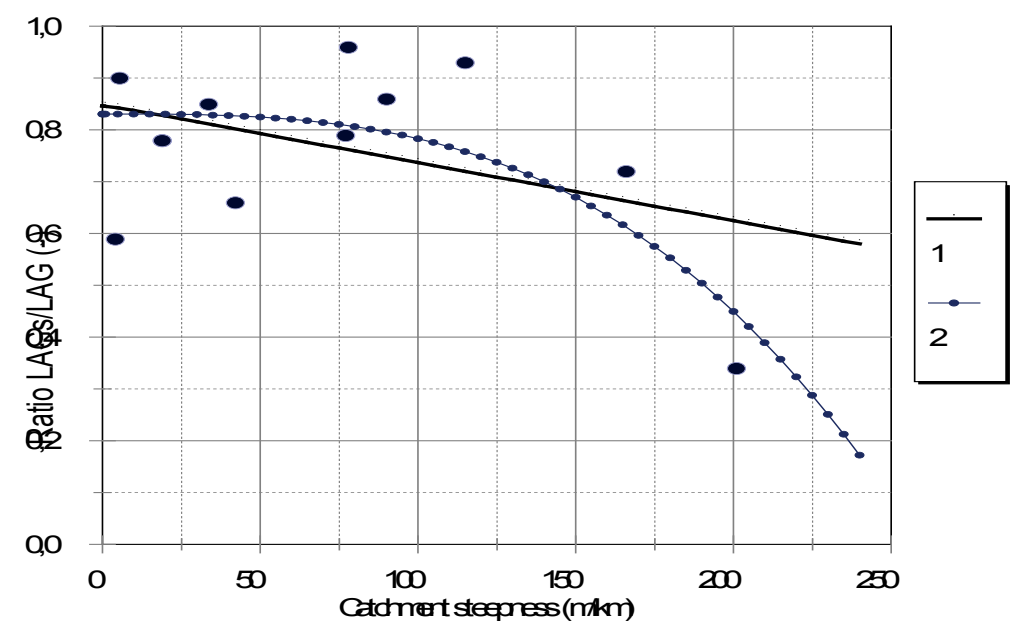

Fig. 1 The relationship between the mean ratio of $L A G_{s} / L A G$ of 11 catchments and their steepness (dots), and linear (1) and exponential (2) approximations of the relationship.

The regression relationship between the mean ratio of $L A G_{s} / L A G$ of the considered catchments and their steepness was established in linear form as:

$$
L A G_{s} / L A G=0.847-0.00112 \Psi
$$

with $\mathrm{r}^{2}=0.162$ and with the standard error of estimation of $L A G_{s} / L A G=0.174$; and in the exponential form as:

$$
L A G_{s} / L A G=0.831-4.76 \cdot 10^{-8} \Psi^{3}
$$

with $\mathrm{r}^{2}=0.467$ and with the standard error of estimation of $L A G_{s} / L A G=0.139$; where $\Psi$ the catchment steepness defined by equation 18 .

The analysis indicates that in the 11 small catchments considered, located in various environmental conditions of climate, topography and land use, the mean value of ratio $L A G_{s} / L A G$ was always smaller then 1 . There is also an indication that the ratio of $L A G_{s} / L A G$ is slightly decreasing with the increase of catchment steepness.

\section{Ratio of lag times for snowmelt events $v s$ rainfall events of a small lowland catchment}

More detailed data are presented for one of the earlier described catchments, i.e. for the Zagożdżonka catchment $\left(23.4 \mathrm{~km}^{2}\right)$ upstream of the Z1 (Czarna) gauge (item 1 in Table 1). The main characteristics of the 21 rainfall events, as well as 16 snowmelt events presented for comparison, are shown in Table 2 . The catchment at this stream gauge has been monitored by the 
Department of Water Engineering of Warsaw University of Life Sciences - SGGW, since 1980, however the rainfall and snowmelt events presented in Table 2 were collected in the period of 2000-2013.

Table 2 Characteristics of the recorded rainfall events and snowmelt events (snowmelt, usually with rain) with their lag times in Zagożdżonka catchment at Z1 (Czarna) gauge.

\begin{tabular}{llllll}
\hline Category & Unit & \multicolumn{2}{c}{ Rainfall events $(21)^{*}$} & \multicolumn{2}{c}{ Snowmelt events (16)") } \\
\cline { 3 - 6 } & & $\begin{array}{l}\text { Value } \\
\text { avg./event }\end{array}$ & Range & $\begin{array}{l}\text { Value } \\
\text { avg./event }\end{array}$ & Range \\
\hline Snowmelt and/or rainfall & & & & & \\
depth, $P_{m}$ & $\mathrm{~mm}$ & 17.3 & $3.0-60.9$ & 30.0 & $5.9-64.0$ \\
Direct runoff, $H$ & $\mathrm{~mm}$ & 1.05 & $0.20-5.16$ & 3.23 & $0.26-16.2$ \\
Peak discharge, $Q_{\max }$ & $\mathrm{m}^{3} \mathrm{~s}^{-1}$ & 0.61 & $0.18-2.08$ & 0.68 & $0.14-3.34$ \\
$Q_{\max } / W Q_{50 \%}$ & - & 0.59 & $0.17-2.00$ & 0.71 & $0.24-3.31$ \\
Peak concentration, $c_{\max }$ & $\mathrm{mg} \mathrm{dm}^{-3}$ & 47.4 & $16.9-213.0$ & 31.2 & $16.0-66.9$ \\
$L A G$ & hours & 7.75 & $2.42-17.2$ & 17.8 & $7.14-31.8$ \\
$L A G_{s}$ & hours & 6.97 & $1.63-12.4$ & 14.7 & $4.99-30.9$ \\
$L A G_{s} /$ LAG & - & 0.90 & $0.67-1.11$ & 0.81 & $0.41-1.20$ \\
\hline
\end{tabular}

${ }^{*}$ numbers in parenthesis are numbers of recorded events; $W Q_{50 \%}$, two-year-flood discharge

The size of the events can be characterised by the peak discharge $\left(Q_{\max }\right)$ related to the twoyear flood $\left(W Q_{50 \%}\right)$. The ratio of the 21 rainfall events was from 0.17 to 2.00 , with an average value of 0.59 . The 16 snowmelt events, which were usually accompanied by rain, were characterised by higher values of the ratio, i.e. from 0.24 to 3.31 , with an average value of 0.71 . The range of the lag times for runoff and lag times for sediment yield, as well as mean values, presented in the Table 2, were significantly larger (over two times) for the snowmelt events than for the rainfall events. The relationship of $L A G_{s} v S L A G$ for individual rainfall and snowmelt events are shown in Fig. 2.

One can see from Fig. 2 that in most cases, for both rainfall events and snowmelt events, the $L A G_{s}$ is smaller than $L A G$ (i.e. $L A G_{s} / L A G<1$ ). There are only five of the 21 rainfall events (Fig. 2(a)), for which the $L A G_{s}$ is larger than $L A G$, and there is only one such case among the 16 snowmelt events (Fig. 2(b)). The average value of the $L A G_{s} / L A G$ of rainfall events is 0.90 and is larger than for snowmelt events, for which average $L A G_{s} / L A G$ is 0.81 (Table 2).
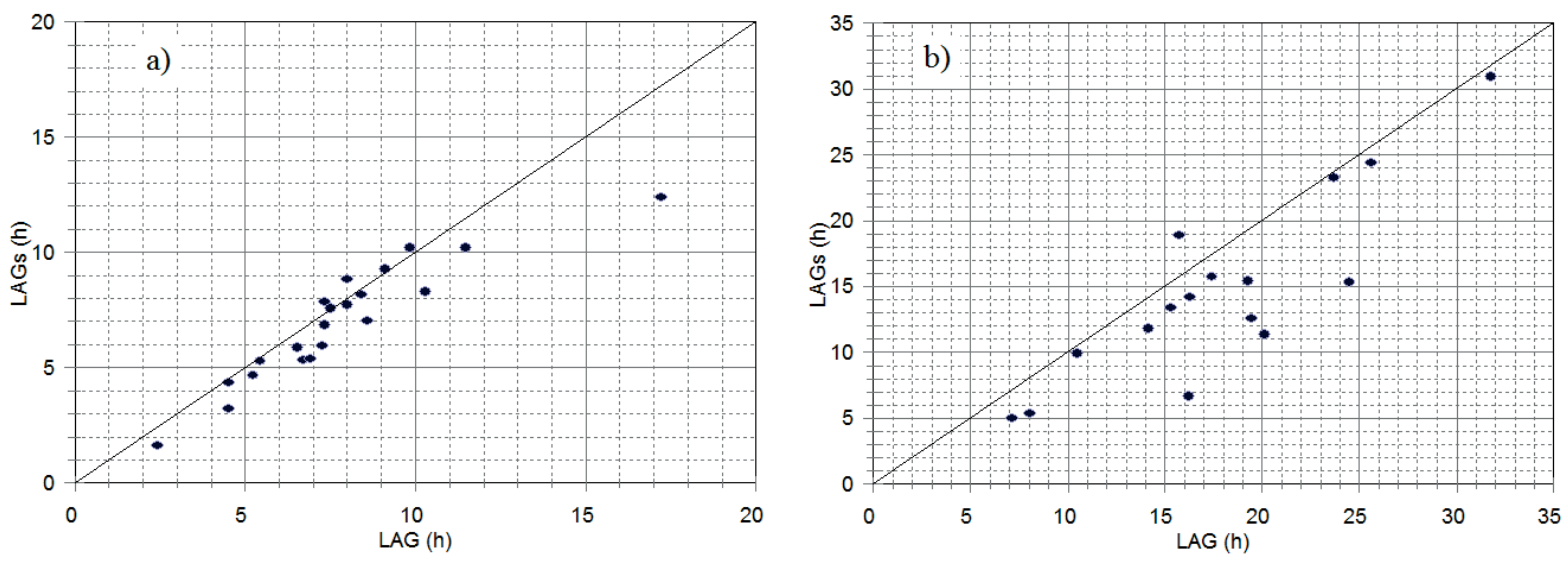

Fig. 2 The relationship of $L A G_{s}$ vs LAG for individual rainfall events (a) and for snowmelt events (b) in the Zagożdżonka catchment at Z1 gauge (the straight lines are lines of equal values). 


\section{CONCLUDING REMARKS}

The analysis of 152 recorded rainfall-runoff-sediment yield events in 11 small catchments located in central and south Poland, central and south Germany, southwest UK and east-central Illinois, shows that:

- the mean values of $L A G_{s} / L A G$ are for all of the considered catchments smaller than 1 and within the range $0.34-0.96$,

- the value of $L A G_{s} / L A G$ decreases with the steepness of the catchment,

- the ratio $L A G_{s} / L A G$ was, for the majority of individual events smaller than one,

- lag times and the relationship between the $L A G_{s}$ and $L A G$ are essential in predicting sedimentgraphs and in estimating the parameters of the instantaneous unit sedimentgraph - IUSG,

- data from other catchments and further study are required to identify the factors controlling the relationship between $L A G_{s}$ and $L A G$.

Analysis of the snowmelt and rainfall events in a small agricultural lowland catchment indicated that lag times, for both runoff and sediment yield, are more than twice as large for snowmelt than for rainfall events. The ratio $L A G_{s} / L A G$ is smaller for snowmelt events then for rainfall events.

Acknowledgements The investigation was carried out with financial support from the PLNational Center of Science (NCN) within the research project N N305 144540. The support provided by the organization is gratefully acknowledged.

\section{REFERENCES}

Banasik, K. (1994) Model sedymentogramu wezbrania opadowego w malej zlewni rolniczej (Sedimentgraph model of rainfall event in a small agricultural watershed, in Polish with an English summary). Theses \& Monographs of Warsaw Agricultural University-SGGW, Warsaw, Poland.

Banasik, K. (1995) A conceptual model of the instantaneous unit sedimentgraph. In: Sediment and Water Quality in River Catchments, ed. by I. D. L. Foster, A. M. Gurnell and B. W. Webb, 97-106. John Wiley and Sons Ltd., Chichester, West Sussex, UK.

Banasik, K., Barszcz, M. and Hejduk, L. (2006) Importance of watershed lag times in IUSG development. In: Sediment Dynamics and the Hydromorphology of Fluvial Systems (Proceedings of a symposium held in Dundee, UK, July 2006). IAHS Publ. 306, 574-581. IAHS Press, Wallingford, UK.

Banasik, K. and Bley, D. (1994) An attempt of modelling of suspended sediment concentration after storm event in an Alpine torent. In: Ergenzinger P., and Schmidt K.-H. (eds), Dynamics and Geomprphology of Mountain Rivers. Springer Verlag, Berlin, 161-170.

Banasik, K., Madeyski, M., Mitchel, J.K. and Mori, K. (2005) An investigation of lag times for rainfall-runoff-sediment yield events in small river basin. Hydrologic Science Journal 50(5), 857-866.

Banasik, K. and Mitchel, J.K. (2008) Conceptual model of sedimentgraph from flood events in a small agricultural watershed. Annals of Warsaw University of Life Sciences - SGGW, Land Reclamation. 39, 49-57; (http://ann landreclam.sggw.pl/z39/art4.pdf).

Banasik, K. and Walling D.E. (1996) Predicting sedimentgraphs for a small agricultural catchment. Nordic Hydrology, 27(4), $275-294$.

Banasik, K. and Woodward, D. E. (1992) Prediction of sedimentgraph from a small watershed in Poland in a changing environment. In: Saving Threatened Resources - in Search of Solution (Proc. of the Irrigation and Drainage Session at Water Forum'92), ed. by Engman, T., 493-498. ASCE, New York.

Barszcz, M., Banasik, K. and Tönsmann F. (2006) Estimation of lag times of rainfall events for three small river basins. EJPAU (Electronic Journal of Polish Agricultural Universities), 9(2), \#30 (http://www.ejpau.media.pl/volume9/issue2/art30.html).

Froehlich, W. (1986) Sediment delivery model for the Homerka drainage basin. In: Drainage Basin Sediment Delivery, ed. by R.F. Hadley (Proceedings of a symposium held at Albuquerque), IAHS Publ. 159, 403-412. IAHS Press, Wallingford, UK.

Froehlich, W. (1991) Sediment production from unmetalled road surfaces. Sediment and Stream Water Quality in a Changing Environment: Trends and Explanation (Proceedings of the Vienna Symposium, August 1991), IAHS Publ. 203, 21-29. IAHS Press, Wallingford, UK.

Johnson, J.W. (1943) Distribution graphs of suspended-matter concentration, Trans. ASCE, 108, 941-964.

Walling, D.E. and Webb B.W. (1982) Sediment availability and the prediction of storm-period sediment yields. In: Recent Development in the Explanation and Prediction of Erosion and Sediment Yield (Proceeding of the Exeter symposium), IAHS Publ. 137, 327-337. IAHS Press, Wallingford, UK.

Williams, J.R. (1978) A sediment graph model based on the instantaneous unit sediment graph. Water Resources Research 14(4), 659-664. 